Journal of Engineering and Applied Sciences 14 (Special Issue 5): 9101-9106, 2019

ISSN: 1816-949X

(C) Medwell Journals, 2019

\title{
Enhanced Dielectrically Properties of Up-Pistachio Peel Composites
}

\author{
Suad H. Aleabi, Inbethaq M.A. Abdulameer, Ayad A. Salih and Shatha H. Mahdi \\ Department of Physics, Ibn AL-Haitham Education College, University of Baghdad, Baghdad, Iraq \\ tagreedmm2000@gmail.com
}

\begin{abstract}
In this research studies the effect of the addition of pistachio peel fillers on the unsaturated polyester matrix by the different weight ratio $(0,5,10,15,20 \mathrm{wt} . \%)$ and study the electrical properties (dielectric constant, loss factor and electrical conductivity). The matrix mixed with each other using by the Hand lay-up method, the electrical properties were studies within arrange of frequencies $(50-1 \mathrm{MHz})$ at room temperature. The electrical conductivity increase with boosting the weight ratio of pistachio peel fillers and increase with increase the voltage and frequency. The dielectric constant decrease with increased frequency and it increases with the increase pistachio peel filler. Loss factor (tan $\bullet$ ) and imaginary dielectric constant decrease with increase the frequency and increase with increase the weight ratio of pistachio peel fillers.
\end{abstract}

Key wards: Pistachio peel, unsaturated polyester, dielectric constant, imaginary dielectric constant, AC conductivity, room temperature

\section{INTRODUCTION}

Composite materials are generally utilized in numerous fields of industry. Contingent upon required properties and there mechanical and electrical properties are essential for about all application in manufacture. Polyester resin is a thermosetting polymer. They have a progression of profitable properties appropriate viscosity, capacity to hardy at both room and high temperature, high quality stockiness and dielectric rings, elevated chemical stability and they don't discharge unstable volatile substances. The light response coefficient of the unsaturated polyester resin is near that of the glass, subsequently the obtainer polymer materials are diaphanous (Rajendran and Marikani, 2004). Specific composite varies from the fiber and chip types in that appropriation of the added substance constituent are normally random as opposed to controlled. Specific composite are thus, generally isotopes.

The particles in specifically composites are discrete and by definition they don't consolidate chemically with the matrix. The geometrical of the particles their structural arrangement action in the matrix to a great extent decide the properties of the composite. These characteristic contain particle size and shape, the separating between the particles, the sum or volume portion of particles and the method in which the particles are disseminated in the matrix. The particles have wide range size from microscope to macroscopic (Schwartz, 1984; Clauser, 1975)
Now a days in many application thermal and electrically conductive polymer-based composites can replace metals. This technology is widely used because it introduce a new material that includes the thermal, insulation and electrical properties of polymer materials. The advantages of polymer over metals are low density, corrosion and oxidation resistance, lightness, Electro Magnetic Interference (EMI) protection, higher chemical resistance and higher producibility. These superior features can be easily adjusted to different and widely applications (Choi et al., 2013; Al-Saleh et al., 2011).

Too many studies in the literature are investigating the addition of nonpolymer fillers to improve the physical properties of polymer. The addition of fillers with high thermal and electrical properties beyonol the neat resin of the composite but cannot reach the level of pure filler materials. The electrical properties of $\left(\mathrm{PMMA}-\mathrm{Al}_{2} \mathrm{O}_{3}\right)$ composite was studied by $\mathrm{B}$. Hussien and he found that the electrical conductivity enhancement with both increasing in the alumina fixations and temperature (Hussien, 2011). Chand and Nigrawal (2008) have studied the DC conductivity behavior of milled carbon fiber reinforced polymer command posited. They found that DC conductivity of these composites increased on increasing the filler content.

Revati et al. (2014) were examined the conducting polymer composites were set up by including diverse level of carbon dark to unsaturated polyester resin. The outcome results demonstrated the electrical conductivity

Corresponding Author: Suad H. Aleabi, Department of Physics, Ibn AL-Haitham Education College, University of Baghdad, Baghdad, Iraq, tagreedmm2000@gmail.com 
of the composite depend on the frequency and it increment with increment the level of carbon black fillers in the polyester composite. The aim of this research determines electrical properties (dielectric constant, loss factor and electrical conductivity) of composite materials consist of un saturated polyesterrein forced by the pistachio peel particles.

\section{MATERIALS AND METHODS}

Unsaturated polyester was used in this study as matrix, the physical properties (liquid), density $\left(1-1.3 \mathrm{~cm}^{3}\right)$ and color (yellow). The resin produces from (Saudi Industrial Resin Limited) company. Use pistachio peel as filler with particle size $(<50 \mu \mathrm{m})$.

Preparation of samples: Pure up prepared with hardener Material using a Methyl Ethyl Ketone Peroxide (MEKP) addition ratio is $(0-5$ and $100 \mathrm{~g})$ of (Up) resin. It has been used an auxiliary material for solidification process (cobalt octoate) an addition ratio (0-0.2-100 g) of resin. $\mathrm{Up} /$ pistachio peel particles in different percentage $(5,10$, $15,20 \mathrm{wt} . \%$ ) mixed with (Up) by (Handlay-up) molding for $10 \mathrm{~min}$ and keep for $24 \mathrm{~h}$ to hardening, therefore, samples were placed in an oven electric at $70^{\circ}$ to complete the hardening process.

Electrical properties: The test includes the dielectric constant, loss tangent $(\tan \bullet)$ and the imaginary dielectric constant at voltage $(10 \mathrm{mV})$ with applied frequency range (50 Hz-1 MHz) using LCR meter model (Rs-232, Taiwan, LCR-8000 G, Drive signal level Ac $(20 \mathrm{~Hz}-5 \mathrm{MHz})$ $\left(0.01 \mathrm{~V} \sim 2 \mathrm{~V}_{\mathrm{ms}}\right.$ ). The dielectric constant, loss tangent (tan -) and the imaginary dielectric constant were calculated by using Eq. 1 and 2 as following Monshi et al. (2012):

$$
\varepsilon^{\prime}=\frac{\mathrm{d} c \mathrm{c}}{\mathrm{A} \varepsilon_{0}}
$$

Where:

- = Dielectric constant

$\mathrm{d}=$ Thickness of sample

$\mathrm{c}=$ The capacitance

$$
\tan \delta=\frac{\breve{\varepsilon}}{\varepsilon^{\prime}} \rightarrow \breve{\varepsilon}=\tan \delta . \varepsilon^{\prime}
$$

where, the imaginary dielectric constant, note that the values of $(\tan \bullet)$ were taken from LCR meter instrument. For the insulating materials, we can study the effect of the temperature and the filler addition on the electrical volume resistivity of polymer composite by using the three electrodes cell or (guard ring electrode technique) and the resistivity $(\bullet)$ value in $(\bullet \mathrm{m})$ of the composite was calculated from Eq. 3 and 4 (Murthy et al., 2003):

$$
\rho=\frac{R A}{L}
$$

Where:

$\mathrm{R}=$ The resistivity of the sample $(\bullet)$

$\mathrm{A}=$ The composite area $\left(\mathrm{m}^{2}\right)$

$\mathrm{L}=$ The length $(\mathrm{m})$

So, the conductivity $(\bullet)$ was calculated by using the relation:

$$
\sigma=\frac{1}{\rho}
$$

\section{RESULTS AND DISCUSSION}

Figure 1 represent the relation between the dielectric constant $(\bullet)$ and applied frequency $950-1 \mathrm{MHz}$ ) in room temperature. The figures show sameness behavior in dielectric constant value for all ratios $(\mathrm{x}=5,10,15,20$ wt.\%) of pistachio peel fillers. The figure show that the dielectric constant $(\bullet)$ decrease with the frequency increase and from the same figure we can observed the dielectric constant $(\bullet)$ increase with pistachio peel fillers increase this called interfacial polarization, this behavior in the frequency above $(50 \mathrm{~Hz})$ but in the frequency below $(1 \mathrm{MHz}$ ) become random with increasing ratio of added fillers, lead to change the space charge polarization and consequently, decrease the dielectric constant $(\bullet)$ with the standard value at frequency $(1 \mathrm{MHz})$ of the polymer (unsaturated polyester resin), we find at all added fillers the dielectric constant values are greater than slandered values at $(50 \mathrm{~Hz})$ (Kakani and Amit, 2004; Zihlif et al., 2010). In general Fig. 2 show that the dielectric constant $(\bullet)$ at frequency $(50 \mathrm{~Hz})$ increase with increase of the amount percent of fillers in sample but in the frequency $(1 \mathrm{MHz})$ decrease with increase the percent of fillers pistachio peel.

The imaginary dielectric constant $(\bullet)$ plotted with frequency $(50-1 \mathrm{MHz})$ in Fig. 3. In general increase of frequency lead to decrease of the imaginary dielectric constant $(\bullet)$ due to an increase in energy loss and this occurs due to the rotation of polar groups. Figure 4 represent the relation between the tangent loss $(\tan \bullet)$ 


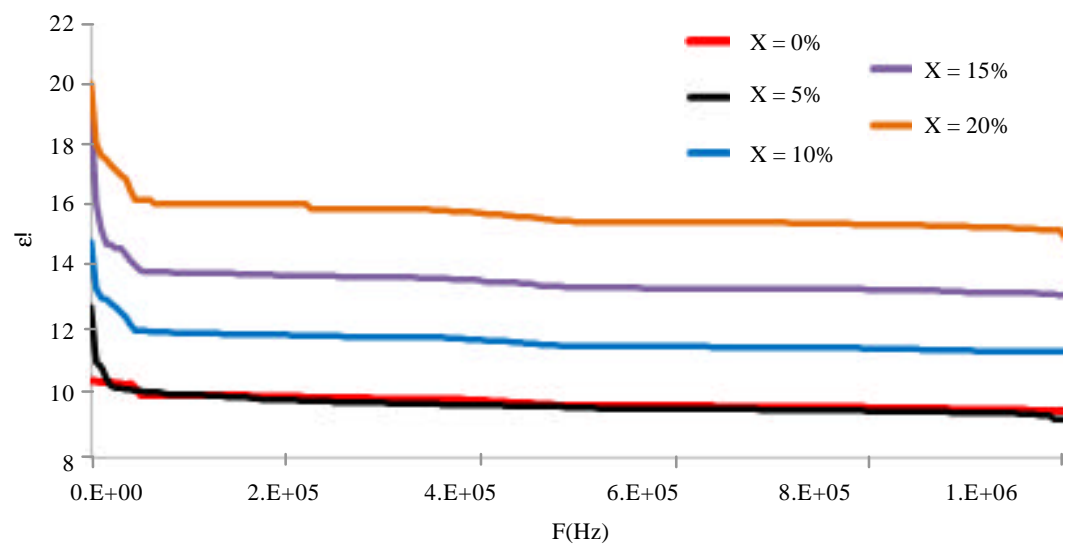

Fig. 1: The variation of dielectric constant with applied frequency for different pistachio peel fillers

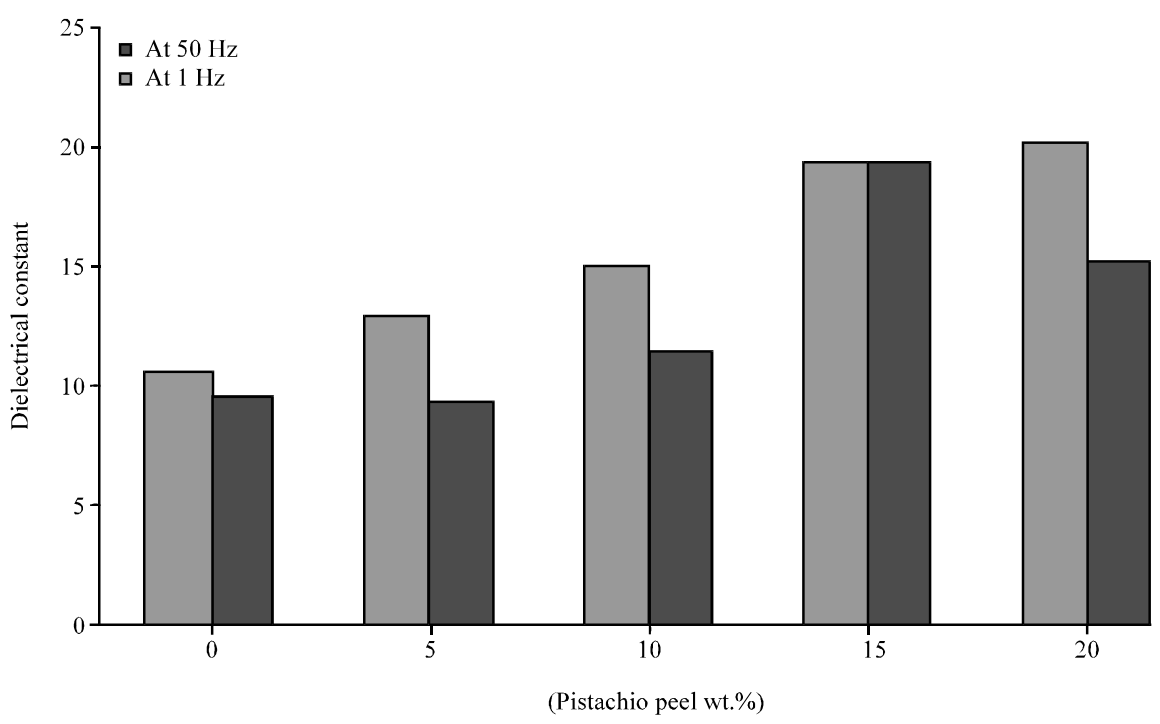

Fig. 2: The variation of the dielectric constant with the pistachio peels filler for the both applied frequency $50 \mathrm{~Hz}$ and $1 \mathrm{MHz}$

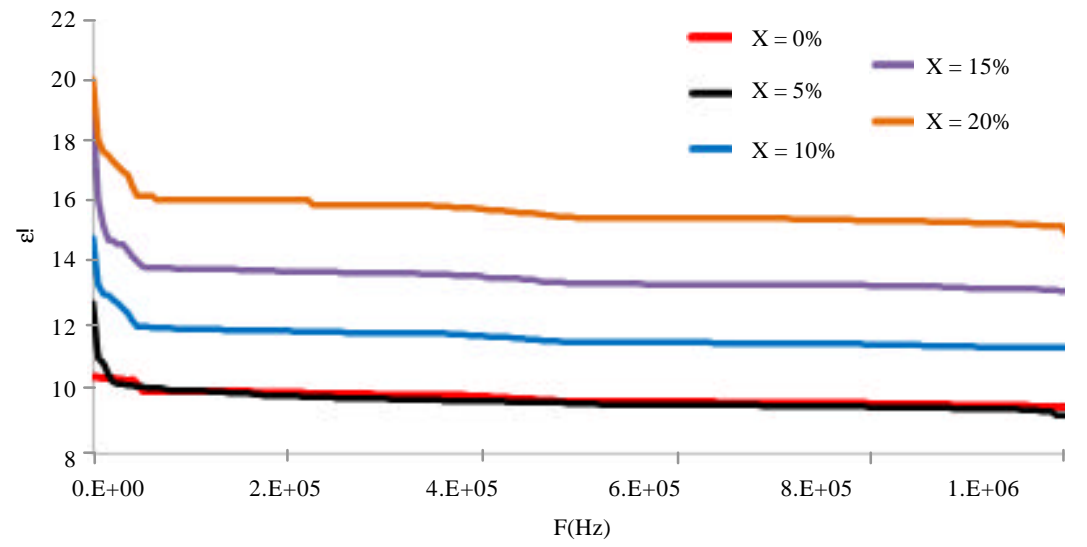

Fig. 3: The variations of the imaginary dielectric constant with the applied frequency for different pistachio peel fillers 


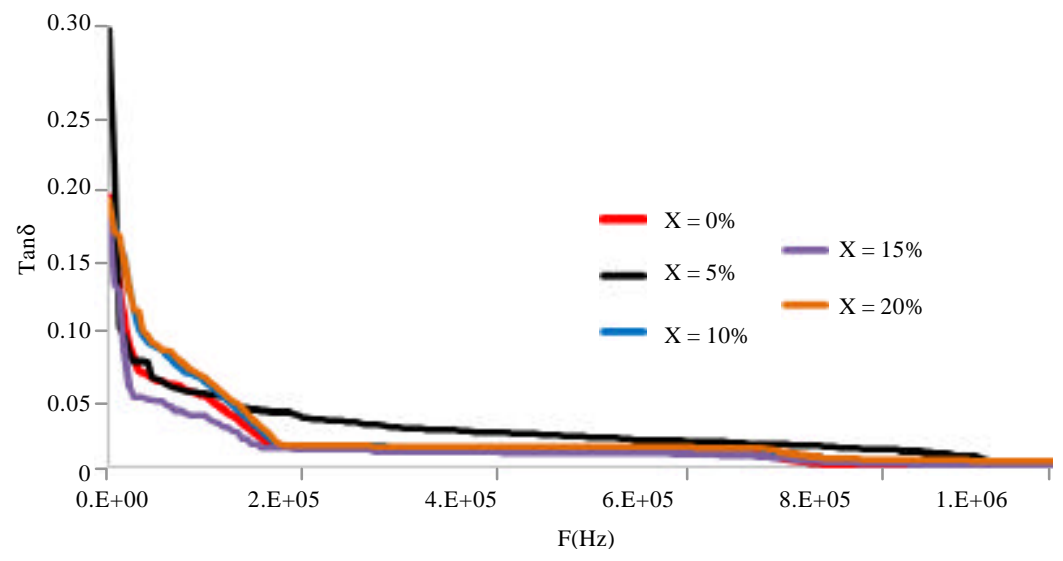

Fig. 4: The relation between the tangent loss with frequency for different pistachio peel fillers

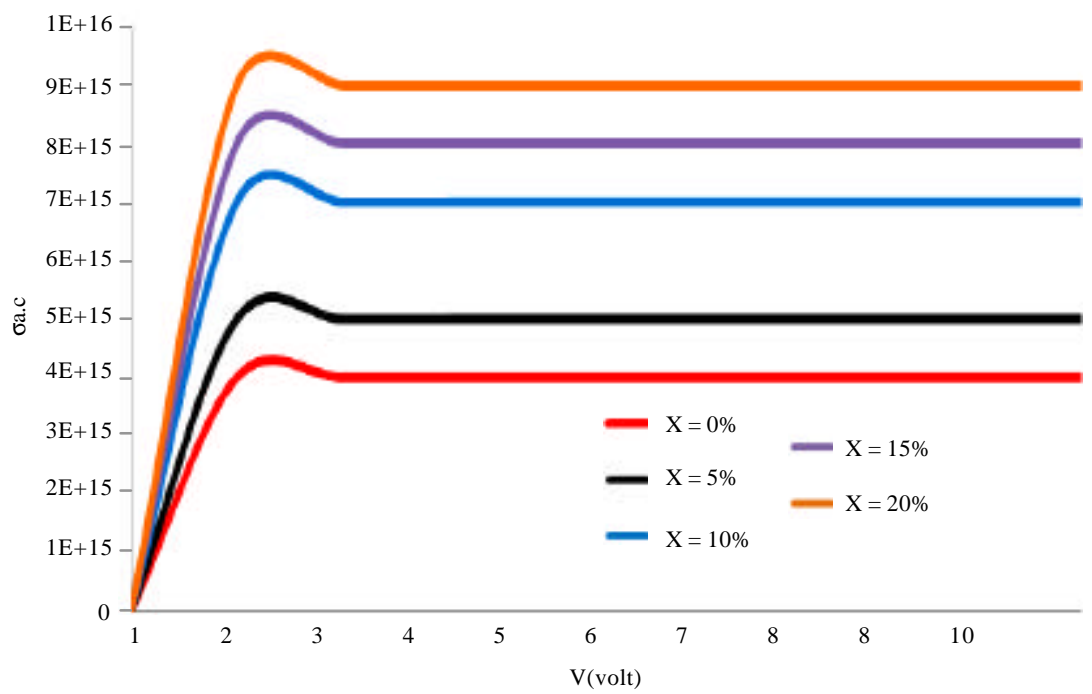

Fig. 5: The relationship between $\mathrm{AC}$ electrical conductivity $\left(\bullet_{\text {ac }}\right)$ with the applied voltage for different pistachio peel fillers

with frequency, we can show that in this figure the absorption energy maxima at $\mathrm{f}=2 \times 10^{5} \mathrm{~Hz}$, this exhibit high value of $(\bullet)$ at this frequency depending on equation $(\tan \cdot=\cdot / \bullet$ ) this zone corresponds as a rule to the area of noticeable relaxation losses. We can note that all of Fig. 4.

Figure 5 represented the relationship between electrical conductivity $(\bullet)$ with the voltage while the Fig. 6 represented the relationship between the $(\ln \bullet)$ with frequency. From these two figures we can observed the increase in the electrical conductivity with increase voltage and increase $(\ln \bullet)$ with increase frequency also and we can saw from the similar figures increment the conductivity with increment the pistachio peel fillers. This expansion could be ascribed to increment segmental mobility of polymers chains close to the fillers particles
(Kawamoto et al., 1974). Likewise, we can decipher this expansion in the electrical conductivity to the expansion of the ionic charge transporters which may be expanded duo to expanding the fillers content (Potty and Khadar, 2000). The conductivity increment with increment frequency we can disclose this nexus as indicated by the resistivity. At the higher frequency the impedance of the sample diminishes fundamentally. The impedance of the sample is overwhelmed by the capacitance of unsaturated polymer matrix (Gojny et al., 2005).

The electrical conductivity of the composite represent the reveres of the resistivity, consequently, the conductivity increments with the expansion of frequency. Figure 7 illustrated the optical micrographs of the morphology for unsaturated polyester and its blends with different percentage of (pistachio peel) fillers. It is clear 


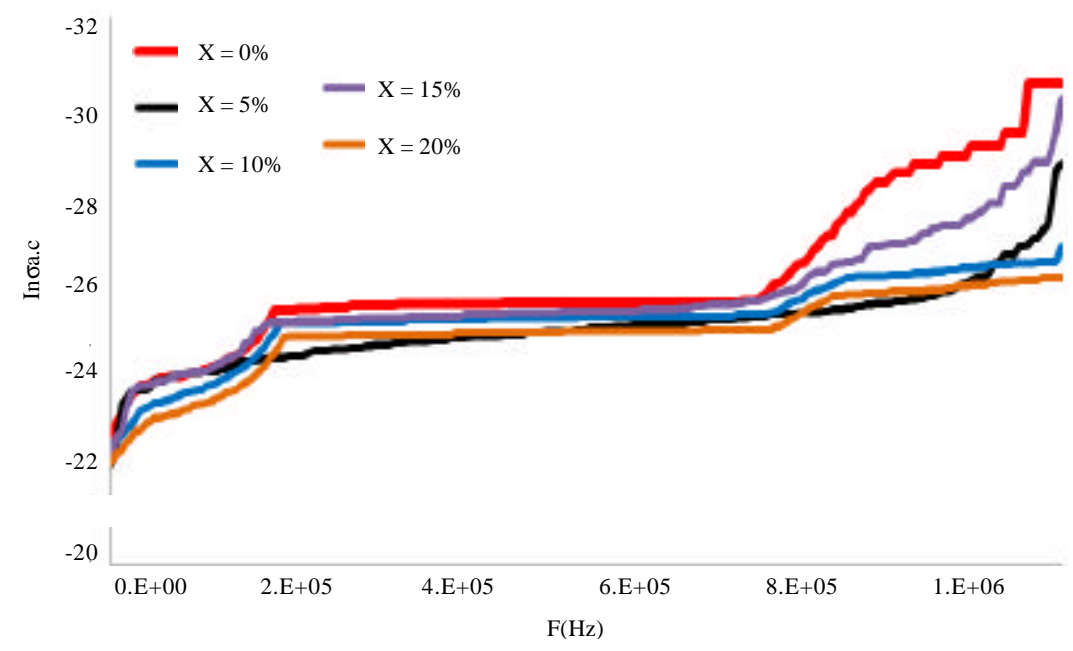

Fig. 6: The relationship between in $\left(\bullet_{a c}\right)$ with the applied frequency for different pistachio peel fillers

(a)

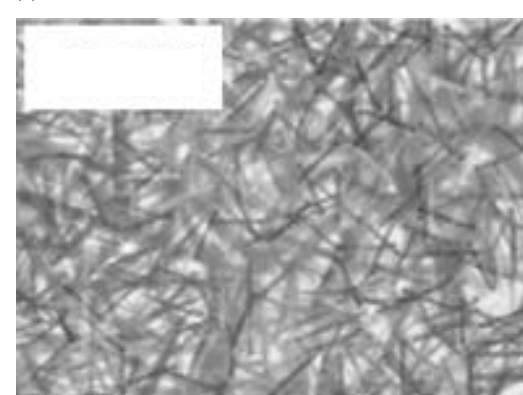

(c)

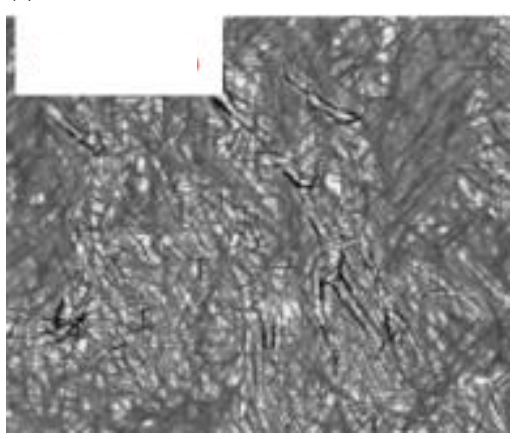

(b)

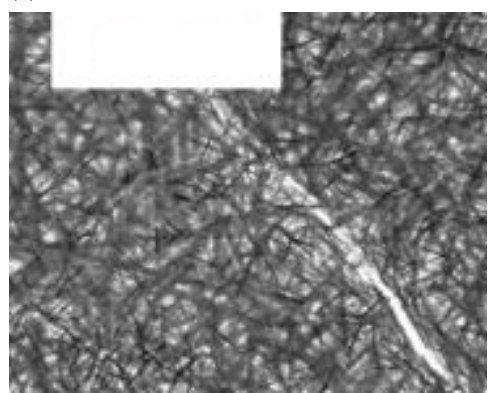

(d)

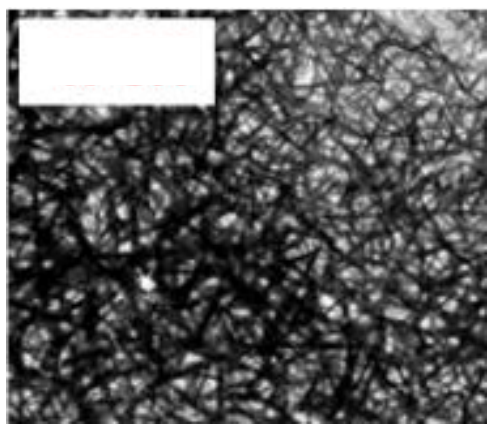

(e)

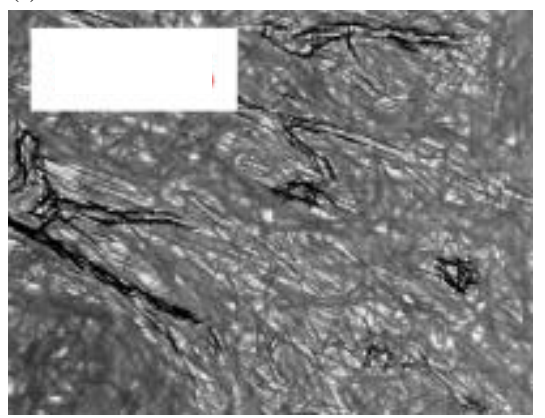

Fig. 7: The optical micrographs of the morphology for unsaturated polyester and its blends with different percentage of (pistachio peel) fillers: a) $X=0 \%$; b) $X=15 \%$; c) $X=10 \%$; d) $X=5 \%$ and e) $X=20 \%$ 
that the best ratio which gives the better miscibility between the polymer and fillers in the ratio $(20 \%)$ while the nature of morphology for the surfaces of samples with lower filler.

\section{CONCLUSION}

From this studies we can observed:

- Increase the dielectric constant $(\bullet)$ for the unsaturated polyester resin after additive the (pistachio peel) fillers

- Decrease the dielectric constant $(\bullet)$ with increase the frequency applied in the range $(50-1 \mathrm{MHz})$

- Decrease the imaginary dielectric constant $(\bullet)$ and the tangent loss (tan •) with frequency for all the percentage ratio filler

- The dielectric constant $(\bullet)$ for all blends (UP-pistachio peel) greater than the pure unsaturated polyester

- The electrical conductivity increases with both increase in the applied voltage and the pistachio peel ratio fillers

\section{REFERENCES}

Al-Saleh, M.H., G.A. Gelves and U. Sundararaj, 2011. Copper nanowire/polystyrene nanocomposites: Lower percolation threshold and higher EMI shielding. Compos. Part A. Appl. Sci. Manuf., 42: 92-97.

Chand, N. and A. Nigrawal, 2008. Investigations on d.c. conductivity behaviour of milled carbon fibre reinforced epoxy graded composites. Bull. Mater. Sci., 31: 665-668.

Choi, S.W., K.H. Yoon and S.S. Jeong, 2013. Morphology and thermal conductivity of polyacrylate composites containing aluminum/multi-walled carbon nanotubes. Comp. Part A: Applied Sci. Manuf., 45: 1-5.

Clauser, H.R., 1975. Industrial and Engineering Materials. McGraw-Hill Company, New York, USA., ISBN:9780070112858, Pages: 440.
Gojny, F.H., M.H. Wichmann, B. Fiedler, W. Bauhofer and $\mathrm{K}$. Schulte, q 2005. Influence of nano-modification on the mechanical and electrical properties of conventional fibre-reinforced composites. Compos. Part A. Appl. Sci. Manuf., 36: 1525-1535.

Hussien, B., 2011. The D.C and A.C electrical properties of (PMMA- $\mathrm{Al}_{2} \mathrm{O}_{3}$ ) composites. Eur. J. Sci. Res., 52: 236-242.

Kakani, S.L. and K. Amit, 2004. Material Science. New Age International Pvt Ltd, New Delhi, India, ISBN: 9788122426564, Pages: 446.

Kawamoto, Y., N. Nagura and S. Tsuchihashi, 1974. Dc conductivity of Ge-S-Ag and As-S-Ag glasses. J. Am. Ceram. Soc., 57: 489-491.

Monshi, A., M.R. Foroughi and M.R. Monshi, 2012. Modified scherrer equation to estimate more accurately nano-crystallite size using XRD. World J. Nano Sci. Eng., 2: 154-160.

Murthy, B.S.R., A.R. Krishna and B.V.R. Krishna, 2003. Thermal analysis of epoxy based fibre-reinforced composites at cryogenic temperatures. J. Inst. Eng. India Mech. Eng. Div., 84: 146-148.

Potty, S.S.N. and M.A. Khadar, 2000. Dielectric properties of nanophase $\mathrm{Ag}_{2} \quad \mathrm{HgI}_{4}$ and $\mathrm{Ag}_{2}$ $\mathrm{HgI} 4-\mathrm{Al}_{2} \mathrm{O}_{3}$ nanocomposites. Bull. Mater. Sci., 23: $361-367$.

Rajendran, V. and A. Marikani, 2004. Materials Science. Tata McGraw-Hill Education, New York, USA., ISBN-13:9780070583696,.

Revati, R., S. Yahud and M.S. Majid, 2014. Electrical properties investigation of unsaturated polyester resin with carbon black as fillers. Appl. Mech. Mater., 554: 145-149.

Schwartz, M.M., 1984. Composite Materials Handbook. McGraw-Hill Company, New York, USA., ISBN:9780070557437, Pages: 651.

Zihlif, A., Y. Ramadin and A.A. Salih, 2010. Electrical properties of poly (Ethylene oxide) polymer doped by $\mathrm{MnCl}$. Ibn Al Haitham J. Pure Appl. Sci., 23: 147-160. 